\title{
Dietary Effects of Pure and Diacylglycerol-rich Rice Bran Oil on Growth Pattern and Lipid Profile of Rats
}

\author{
Rupali Dhara ${ }^{1}$, Pubali Dhar ${ }^{2}$ and Mahua Ghosh ${ }^{1 *}$ \\ ${ }^{1}$ Dept. of Chemical Technology, University of Calcutta \\ ${ }^{2}$ Dept. of Home Science, University of Calcutta
}

\begin{abstract}
Diacylglycerol (DAG) oil is becoming quite well known for its beneficial effects on obesity and weight related disorders as they are digested and metabolized in a different way, which significantly reduces body weight. The present study was conducted to evaluate the nutritional effect of rice bran oil (RBO) and DAG-rich rice bran oil on rat model. DAG-rich RBO $(46.10 \%$ DAG) was prepared in the laboratory by enzymatic (TLIM) glycerolysis process. For the feeding experiment, rats (average body weight $130 \mathrm{~g}$ ) were divided into two groups, each consisting of eight rats. Group RBO was taken as control while DAG-rich RBO (Group DGR) was taken as experimental. Food efficiency ratio, lipid profile of plasma, liver, mesentery and erythrocyte membrane (EM) lipid profile, plasma leptin content, HMG-CoA reductase activity were measured using standard procedures. The results indicated that DAG-rich rice bran oil significantly decreased body weight of rats and content of total cholesterol and triglyceride in plasma compared to the control RBO. The long term use of DAG-rich rice bran oil might be useful for prevention of obesity and incidence of hypercholesterolemia.
\end{abstract}

Key words: Diacylglycerol (DAG)-rich rice bran oil, lipid profile, cholesterol, leptin, HMG-CoA reductase

\section{Introduction}

Obesity has become a major pandemic. Globally, the incidence and prevalence of obesity continue to increase at alarming rates as obesity is associated with increased health risks for chronic diseases such as heart disease, hypertension, diabetes, and cancer. Excess body weight is the result of an imbalance between energy intake(EI) and energy expenditure (EE), by which surplus EI is stored as triglyceride in adipose tissues. Although weight loss can be readily achieved experimentally, long-term weight maintenance is often unsuccessful. Dietary modification can be one of the solutions to combat this menace. In human populations, fats and oils consumption account for $38 \%$ of total calories in the diet; therefore, it would be beneficial to have a dietary fat with anti-obesity properties. Vegetable oils rich in essential fatty acids, medium chain, short chain, very long chain fatty acids are now used for the production of nutraceuticals such as monoacylglycerol (MAG) and diacylglycerol (DAG) rich oils which has been found to reduce obesity as well as serum cholesterol due to their different metabolism pathway compared to triacylglycerol (TAG) rich oils $^{1,2)}$. Nagao et $a l^{3}$. reported that structurally produced DAG reduces body weight gain that accompanies the stim- ulation of intestinal lipid metabolism. Studies also suggested that long-term ingestion of dietary DAG composed mainly of 1, 3 DAG decreases both body weight and visceral fat mass in humans, in comparison with TAG ingestion. Couillard et $a l^{4}$. examined potential differences in postprandial triglyceride-rich lipoprotein (TRL) responses in subjects characterized by high versus low levels of visceral adipose tissue and they found that both excess body fat and visceral obesity were associated with increased postprandial TAG responses in total TRL $(\mathrm{r}=0.33-0.45)$.

Diacylglycerol (DAG) oil is natural component of edible vegetable oils. Recent studies have indicated that $D A G$ is effective for fasting and postprandial hyperlipidemia and for preventing excess adiposity. The main nutritional functions of DAG rich oils are suppression of postprandial serum triglyceride elevation and suppression of body fat accumulation $^{3,5}$. DAG oil not only has the highly emulsifying characteristics, but it is also able to retain a large volume of water. One volume of TAG oil is able to emulsify only 0.97 volume of water, where as one volume of DAG oil is able to emulsify 5.53 volumes of water. The presence of a single hydroxyl group in the molecule may lead to the difference in emulsification properties between DAG and

\footnotetext{
*Correspondence to: Mahua Ghosh, Dept. of Chemical Technology, University of Calcutta (92, A. P. C. Road, Kolkata 700 009 , INDIA)

E-mail: mahuag@gail.com/

Accepted February 3, 2012 (received for review September 16, 2011)

Journal of Oleo Science ISSN 1345-8957 print / ISSN 1347-3352 online

http://www.jstage.jst.go.jp/browse/jos/ http://mc.manusriptcentral.com/jjocs
} 


\section{R. Dhara, P. Dhar and M. Ghosh}

$\mathrm{TAG}^{6,7)}$. Results from studies in animals and humans demonstrate that DAG oil has metabolic characteristics distinct from those of TAG oil, although the two have a similar fatty acid composition, and that this characteristic can be beneficial in preventing and managing the accumulation of visceral fat and the postprandial elevations of triacylglycerol in serum and chylomicron ${ }^{8)}$. Kamphuis et $\mathrm{al}^{9)}$ also reported that consumption of DAG oil instead of TAG oil increased fat oxidation in healthy humans. This study also indicated that a single ingestion of DAG oil not only increases fat oxidation, it might be more easily oxidized than TAG oil and thus an anti-obese effect results. Several studies with humans had also demonstrated that DAG ingestion reduced postprandial hypertriglyceridemia compared with TAG ingestion ${ }^{10)}$.

Rice bran(Oryza sativa) oil(RBO) is currently popular edible oil used in several countries especially in Asian countries. RBO contains about $4 \%$ of unsaponifiable fraction in which $1.8-2 \%$ is phytosterol and $1.0-2.0 \%$ is oryzanol. Among the phytosterols, RBO has a greater content of tocopherols and tocotrienols which provide oxidative stability to the oil. RBO is recommended for the treatment of hyperlipoproteinemias in humans because plasma total cholesterol(TC), low-density lipoprotein cholesterol(LDLC), and triglyceride (TG) concentrations decrease when this oil is added to the diet ${ }^{11-15)}$. It is a MUFA rich (oleic $45 \%$ ) oil with appreciable amount of linoleic acid (32\%). The health benefits of RBO are now well established.

Our previous study established that DAG rich mustard oil reduces TC, TG, non-high density lipoprotein (nonHDL) cholesterol and raises HDL cholesterol even when cholesterol had been supplemented in the diet DAG rich mustard oil fed rats also showed significant decrease in plasma leptin content indicating that they are less obese than the control (normal mustard oil) ${ }^{16)}$. The present study was designed to compare the anti-obesity and hypocholesterolomic effect of DAG rich RBO compared to normal $\mathrm{RBO}$ on rat model. This investigation included growth response, food efficiency ratio (FER), lipid profile of plasma such as TC, HDL-cholesterol, non-HDL cholesterol, TG, phospholipid, plasma leptin content, lipid spectrum (total lipid content, total cholesterol, triacylglycerol, phospholipid) of liver, mesentery and erythrocyte membrane (EM), HMG-CoA reductase activity in liver.

\section{Materials and Methods}

\subsection{Materials}

Refined RBO was obtained from M/s Sethia Oil Mills Ltd, Burdwan, West Bengal, India. Enzyme TLIM(Thermomyces lanuginose) was a gift of M/s Novozymes India Ltd., Bangalore, India. It is an immobilized position specific lipase. Glycerol and all other reagents used were of AR grade and procured from Merck India Ltd. Mumbai, India.

\subsection{Glycerolysis reaction}

Refined rice bran oil and glycerol were taken in a molar ratio of 1: 2 and 10\% (w/w, on the basis of total substrate weight) enzyme TLIM was added and the reaction was carried out at constant temperature of $60^{\circ} \mathrm{C}$ with constant stirring of $200 \mathrm{rpm}$ with a magnetic stirrer for $5 \mathrm{hr}$ under vacuum. Samples were withdrawn intermittently from the reaction mixture and analyzed for amount of DAG produced. The final product was filtered to separate the enzyme and washed with water to remove excess glycerol, vacuum dried, and stored at $-20^{\circ} \mathrm{C}$ for feeding experiment.

\subsection{Estimation of DAG and MAG content in dietary oils}

HPTLC analysis was done to estimate MAG and DAG (\% $\mathrm{w} / \mathrm{w})$ present in the dietary oils ${ }^{17)}$. The extracted lipids were separated by TLC using a Silica gel 60-precoated high-performance TLC (HPTLC) plate (Merck, Germany) and hexane/diethyl ether/acetic acid (80:20:1, by vol) as the development solvent. For quantification of DAG, HPTLC plates were sprayed with $40 \%$ sulfuric acid, immediately heated to $180^{\circ} \mathrm{C}$ to visualize the lipids, and used for densitometry. The integrated optical density (IOD) of the lipids was measured using a WINCATS-3 software program, CAMAG-HPTLC Scanner 3" (Scanner 3_ 130214" S/N 130214). Standards for sn-1,2-DAG (99\% pure, Siga) and 1,3-DAG (98\% pure, Sigma Aldrich) and 1 and 2-MAG (prepared in the laboratory) were applied to the plate, and the calibration curves were constructed by plotting the IOD vs the amount of lipid loaded. The standard curve was linear and the value of the IOD of the lipid was interpolated on the corresponding calibration curve.

\subsection{Gas Liquid Chromatography (GLC)}

Gas-liquid chromatography technique was employed for the determination of fatty acid composition of different dietary oils after converting them into methyl esters by Litchfield' s method ${ }^{18)}$

\subsection{Feeding experiment}

The animal experiments were performed with the approval of the Ethics Committee for experimental animals of the Department of Chemical Technology (University of Calcutta). The animal experiment was designed on the basis of earlier reports published from this laboratory. Male albino rats (average body weight-170 g) of Charles Foster strain (selected for the authenticity of the strain) were chosen as animal system for feeding experiment. Rats were housed individually in stainless steel cages $(27 \times 21 \times 14$ $\mathrm{cm}^{3}$ ) with mesh floors in a room maintained under constant temperature $\left(25-30^{\circ} \mathrm{C}\right)$ and a $12 \mathrm{hr}$ light/12 hr dark cycle (appropriate light and dark cycle is responsible to maintain 
the biological rhythm which maintains hormonal cycles that in turn controls the lipid metabolism). Following a 7 days adaptation during which the animals were maintained on a standard diet and water ad libitum. Each group of rats received different experimental oil while the other dietary components were same. The rats were fed balanced diet ${ }^{19}$ having the following composition: fat free casein$18 \%$ (protein source), fat-20\%, starch-55\% (carbohydrate source), Salt mixture $4 \%$ [composition of salt mixture No. 12 (wt in g): NaCl-292.5; $\mathrm{KH}_{2} \mathrm{PO}_{4}-816.6 ; \mathrm{MgSO}_{4}-120.3$; $\mathrm{CaCO}_{3}-800.8 ; \mathrm{FeSO}_{4}, 7 \mathrm{H}_{2} \mathrm{O}-56.6$; KCl-1.66; $\mathrm{MnSO}_{4}, 2 \mathrm{H}_{2} \mathrm{O}-$ 9.35; $\mathrm{ZnCL}_{2}-0.5452 ; \mathrm{CuSO}_{4}, 5 \mathrm{H}_{2} \mathrm{O}-0.9988 ; \mathrm{CoCl}_{2}{ }^{-}, 6 \mathrm{H}_{2} \mathrm{O}-$ $0.0476]$; cellulose-3\%; and one multivitamin capsule (Vitamin A I.P. 10,000 units, thiamine mononitrate I.P.5 mg, vitamin B.I.P. $5 \mathrm{mg}$, calcium pantothenate USP $5 \mathrm{mg}$, niacinamide I.P. $50 \mathrm{mg}$, ascorbic acid I.P. 400 units, cholecalciferol USP 15 units, menadione I.P. $9.1 \mathrm{mg}$, folic acid I.P. $1 \mathrm{mg}$, and vitamin E USP $0.1 \mathrm{mg}$ ) per $\mathrm{kg}$ of diet. The diet was adequate in all nutrients. The animals were divided into 2 groups (average body weight $170 \mathrm{~g}$ ), each consisting of eight animals, naming RBO and DGR group received normal mustard oil as dietary lipid, RBO (control) group was fed with refined RBO; DGR group (experimental) was fed with DAG rich RBO. Following table describes the details of feeding groups.

The amount of daily diet consumed by each rat and weekly body weight gain were noted. The Food Efficiency ratio (FER) of each rat was calculated by the following equation:-

FER = Body weight gain/ Food consumed .

At the end of 28 days of experimental period rats were fasted over-night for $12 \mathrm{hr}$ and then sacrificed under anesthesia using chloroform. The abdomen was opened, blood samples was collected from hepatic vein into clear heparinised centrifuge tube and centrifuge at low speed (3000 g, $4^{\circ} \mathrm{C}$ ) for $10 \mathrm{~min}$ to isolate the plasma. Plasma was separated as the supernatant layer and was collected carefully without disturbing the rest lower part. The liver and mesentery were immediately excised, cleaned by washing with saline $(0.98 \% \mathrm{NaCl} \mathrm{sol})$, blotted, weighed and stored at deep freeze temperature $\left(-40^{\circ} \mathrm{C}\right)$ for subsequent extraction of tissue lipid.

\subsection{Lipid analysis}

According to the standard methods, the lipid compo- nents such as total cholesterol ${ }^{20)}$ and high-density lipoprotein (HDL)-cholesterol ${ }^{21)}$ and triacylglycerol (TAG) ${ }^{22)}$ of plasma were analyzed using enzymatic kits Ecoline CHOD PAP method, supplied by Merck India Ltd., Mumbai, India.

\subsection{Preparation of EM ghost}

After plasma separation, the red blood cells (RBC) were washed three times by centrifugation at $3000 \mathrm{~g}$, for $10 \mathrm{~min}$ with three volumes of a cooled isotonic solution containing $0.15 \mathrm{M} \mathrm{NaCl}$ and $10^{-5} \mathrm{M}$ EDTA. RBC was haemolysed using hypotonic solution and centrifuged at 20,000 g for $40 \mathrm{~min}$ in a cold centrifuge at $4^{\circ} \mathrm{C}$. The supernatant was removed carefully with a pasteur pipette. The process was repeated two more times. After the last wash step, the supernatant was removed as much as possible and the loosely packed milky-looking membrane pellet was re-suspended at the bottom of the tube using $0.89 \% \mathrm{NaCl}$ solution. Concentrated membrane solution was taken in $2 \mathrm{ml}$ screw cap vial and stored at $-4^{\circ} \mathrm{C}^{23)}$.

\subsection{Liver and mesentery tissue lipid extraction}

Total lipids were extracted from an aliquot of tissue homogenate by the method of Bligh and Dyer ${ }^{24)}$.

\subsection{Estimation of total protein}

Total protein was estimated by the method of Lowry et $\mathrm{al}^{25)}$.

\subsection{Estimation of phospholipids}

Phospholipid content in tissue lipid was determined by estimating phosphorous according to the method of Chen et $\mathrm{al}^{26)}$.

\subsection{Measurement of HMG CoA: Mevalonate Ratio}

To measure the HMG CoA reductase activity an indirect method was used ${ }^{27)} .1 \mathrm{~g}$ of fresh liver tissue was homogenized in $10 \mathrm{ml}$ saline-arsenate solution and equal volume of diluted perchloric acid was added and kept for 5 min. After centrifugation at $2000 \mathrm{rpm}$ for $10 \mathrm{mins}, 1 \mathrm{ml}$ of the filtrate was utilized for HMG Co-A analysis with $0.5 \mathrm{ml}$ alkaline hydroxylamine ( $\mathrm{pH} 5.5$ ) and $1.5 \mathrm{ml}$ ferric chloride and $1 \mathrm{ml}$ of the filtrate was utilized for measuring the mevalonate with $0.5 \mathrm{ml}$ acidic hydroxylamine $(\mathrm{pH}$ 2.1) and ferric chloride. The absorbance was measured at $540 \mathrm{~nm}$.

Food composition of different dietary groups.

\begin{tabular}{ccccc}
\hline Animal & Groups & Composition of Diet & Dose & Duration \\
\hline $\begin{array}{c}\text { Male } \\
\text { Albino Rat } \\
\text { (Charles } \\
\text { Foster }\end{array}$ & Control RBO & $\begin{array}{c}\text { Balanced diet }+20 \% \text { refined rice } \\
\text { bran oil }\end{array}$ & $\begin{array}{c}10 \mathrm{~g} \text { of } \\
\text { food } / \mathrm{rat} / \\
\text { day }\end{array}$ & 28 days \\
\cline { 2 - 3 } & DGR & $\begin{array}{c}\text { Balanced diet }+20 \% \text { DAG rich } \\
\text { rice bran oil }\end{array}$ & & \\
\hline
\end{tabular}




\subsection{Measurement of leptin}

Leptin content was measured using ELISA Kit procured from LINCO Research, MO, USA[Cat. No. E6083-K] by the method provided with the kit.

\subsection{Statistical analysis}

The data was expressed as mean \pm standard error of mean (SEM). One-way analysis of variance (ANOVA) was also used for statistical analysis between groups. F ratio of one-way ANOVA is significant when p value $<0.05$. Tukey's multiple range method ${ }^{28)}$ was used for comparison. For statistical analysis Origin 7 software was used to calculate the results.

\section{Results and Discussion}

DAG-rich rice bran oil (DGR) was used as experimental oil in comparison to normal rice bran oil which was used as control oil. Table 1 shows DAG content, oryzanol content and the fatty acid composition of original rice bran oil and DAG rich rice bran oil.

Food Efficiency Ratio (FER) of different dietary groups is tabulated in Fig. 1. From the figure it is evident that that the DAG fed rats showed a significant decrease in FER in the $2^{\text {nd }}, 3^{\text {rd }}$ and $4^{\text {th }}$ weeks compared to the RBO fed group. It has also been seen that the reduction in FER of the RBO fed rats have not been significant commencing from $3^{\text {rd }}$ and $4^{\text {th }}$ weeks respectively compared to the first two weeks where no reduction in FER was observed. Thus it can be well asserted that DGR significantly reduced body weight compared to control RBO group. In control feeding studies it was observed that DAG prevented the accumulation of body weight and fat associated with the high fat and high sucrose diet in obesity prone mice ${ }^{29)}$. These effects do not appear due to the poor digestibility or reduced energy

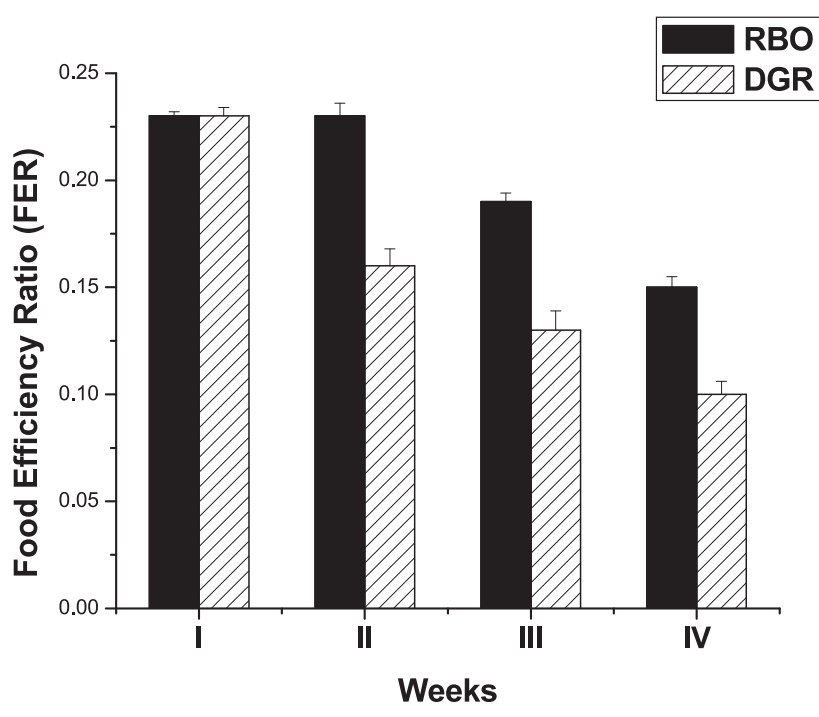

(all values are mean \pm SEM, $n=8$ )

Fig. 1 Food efficiency ratio of two dietary groups. RBO : Rats fed with rice bran oil DGR : Rats fed with DAG-rich rice bran oil

content of DAG as the apparent digestibility of DAG and TAG oils are identical (96.3\%)in rats, and the energy content measured in a bomb calorimeter is also similar (38.9 and $39.6 \mathrm{~kJ} / \mathrm{kg}$ for DAG and TAG respectively ${ }^{30)}$. Therefore, decreased body weight is due to increased energy expenditure or due to food or due to both ${ }^{31)}$. Watanabe et $\mathrm{al}^{32}$ found that in comparison with a TAG control, oxygen consumption in rats increased by $1 \mathrm{ml} \mathrm{kg}^{-1} \cdot \mathrm{min}^{-1}$ 90 min after DAG administration that suggests a short term increase in energy expenditure. Similarly the weight of individual organ like liver, mesentery etc. of RBO group was greater than the DAG group which also supports the less deposition of fat in individual tissues also in case DAG ingestion.

Table 1 Composition of original rice bran oil and DAG-rich rice bran oil.

\begin{tabular}{lccc}
\hline $\begin{array}{l}\text { Dietary Oils } \rightarrow \\
\begin{array}{l}\text { Parameters } \\
\downarrow\end{array}\end{array}$ & $\begin{array}{c}\text { Original Rice Bran } \\
\text { Oil (RBO) }\end{array}$ & $\begin{array}{c}\text { DAG-Rich Rice } \\
\text { Bran Oil (DGR) }\end{array}$ \\
\hline Amount of total DAG (\% w/w) & & $1.10 \pm 0.04$ & $46.4 \pm 0.53$ \\
Amount of 1, 3 DAG (\% w/w) & nd & $66.42 \pm 0.56$ \\
Amount of 1, 2 DAG (\% w/w) & & nd & $33.58 \pm 0.91$ \\
Amount of Oryzanol $(\% \mathrm{w} / \mathrm{w})$ & & $1.11 \pm 0.01$ & $1.02 \pm 0.05$ \\
Fatty acid composition $(\% \mathrm{w} / \mathrm{w}):$ & $16: 0$ & $16.56 \pm 0.04$ & $17.26 \pm 0.1$ \\
& $18: 0$ & $1.87 \pm 0.01$ & $1.69 \pm 0.08$ \\
& $18: 1$ & $44.89 \pm 0.08$ & $46.41 \pm 0.01$ \\
& $18: 2$ & $34.38 \pm 0.01$ & $34.16 \pm 0.08$ \\
& $18: 3$ & $0.26 \pm 0.05$ & $0.44 \pm 0.45$ \\
\hline
\end{tabular}

nd-not determined

Values are mean $\pm \mathrm{SD}, \mathrm{n}=3$ 
Table 2 Plasma Lipid Profile of Rats of Different Dietary Groups.

\begin{tabular}{ccccc}
\hline Groups & $\begin{array}{c}\text { Total Cholesterol } \\
(\mathrm{mg} / \mathrm{dL})\end{array}$ & $\begin{array}{c}\text { HDL-Cholesterol } \\
(\mathrm{mg} / \mathrm{dL})\end{array}$ & $\begin{array}{c}\text { Non-HDL } \\
\text { Cholesterol }(\mathrm{mg} / \mathrm{dL})\end{array}$ & TAG (mg/dL) \\
\hline RBO & $87.63 \pm 2.81^{*}$ & $19.60 \pm 1.36$ & $68.04 \pm 1.28^{\mathrm{b}}$ & $81.5 \pm 2.15$ \\
DGR & $63.4 \pm 1.76^{*}$ & $20.21 \pm 1.54$ & $43.19 \pm 1.24^{\mathrm{b}}$ & $74.48 \pm 1.92$ \\
\hline
\end{tabular}

All values are means of 8 rats/ diet \pm SEM; (See Fig. 1 for other abbreviations)

* RBO vs. DGR significant, $\mathrm{p}<0.05$

${ }^{\mathrm{b}} \mathrm{RBO}$ vs. DGR significant, $\mathrm{p}<0.01$

Table 3 Liver and mesentery lipid profile of rats of different dietary groups.

\begin{tabular}{ccccccccc}
\hline \multirow{2}{*}{ Groups } & \multicolumn{2}{c}{$\begin{array}{c}\text { Total lipid } \\
\text { (mg/g of tissue) }\end{array}$} & \multicolumn{2}{c}{$\begin{array}{c}\text { Total Cholesterol } \\
\text { (mg/g of tissue) }\end{array}$} & \multicolumn{2}{c}{$\begin{array}{c}\text { TAG } \\
\text { (mg/g of tissue) }\end{array}$} & \multicolumn{2}{c}{$\begin{array}{c}\text { Phospholipid } \\
\text { (mg/g of tissue) }\end{array}$} \\
\cline { 2 - 10 } & Liver & Mesentery & Liver & Mesentery & Liver & Mesentery & Liver & Mesentery \\
\hline RBO & $214 \pm 1.31$ & $287 \pm 1.61^{*}$ & $32.48 \pm 1.35^{\mathrm{c}}$ & $44.33 \pm 3.61^{\mathrm{b}}$ & $162.54 \pm 1.98^{\text {aa }}$ & $236.87 \pm 1.75^{\mathrm{a}}$ & $16.15 \pm 1.38^{\mathrm{d}}$ & $16.73 \pm 1.62$ \\
DGR & $197 \pm 2.05$ & $263 \pm 2.74^{*}$ & $29.66 \pm 1.01^{\mathrm{c}}$ & $34.96 \pm 1.76^{\mathrm{b}}$ & $146.27 \pm 1.32^{\text {aa }}$ & $204.16 \pm 1.9^{\text {a }}$ & $20.1 \pm 1.03^{\mathrm{d}}$ & $15.65 \pm 1.20$ \\
\hline
\end{tabular}

All values are means of 8 rats/ diet \pm SEM; (See fig. 1 for other abbreviations)

*RBO vs. DGR significant, $\mathrm{p}<0.05 \quad{ }^{\mathrm{a}} \mathrm{RBO}$ vs. DGR significant, $\mathrm{p}<0.01$

${ }^{b}$ RBO vs. DGR significant, $\mathrm{p}<0.01 \quad{ }^{a a} \mathrm{RBO}$ vs. DGR significant $\mathrm{p}<0.05$

${ }^{\mathrm{c}} \mathrm{RBO}$ vs. DGR significant, $\mathrm{p}<0.05 \quad{ }^{\mathrm{d}} \mathrm{RBO}$ vs. DGR significant, $\mathrm{p}<0.01$

In plasma lipid profile, DGR group showed significant decrease in total cholesterol, non-HDL cholesterol and TG content compared to RBO group (Table 2). Experimental studies in animals and humans showed that DAG (mainly 1,3 DAG) decreases postprandial triglyceridemia in comparison with a TAG control ${ }^{8,33)}$. It was reported that dietary DAG has anti-obesity activity and prevents postprandial hypertriacylglycerolemia in experimental animals and humans ${ }^{31,34,35)}$. Ikuo Ikeda and Teruyoshi Yanagita suggested that delayed absorption of DAG compared to TAG may be the important determinant in preventing body fat accumulation. During the period of high insulin levels in blood after a meal, the amount of chylomicron TAG entering the blood stream after DAG consumption is less than that of TAG because lymphatic transport of TAG is delayed after the feeding of DAG. With the reduction of concentration of blood insulin deposition of fatty acid from chylomicron TAG is decreased and used for energy expenditure. Therefore, fatty acid from chylomicron TAG after DAG feeding may be utilized preferentially for fatty acid oxidation rather than for body fat accumulation ${ }^{36)}$.

Liver and mesentery lipid profiles are tabulated in Table 3. The data indicates significant decrease in total cholesterol content in liver lipid in DGR group compared to RBO group. DGR group showed significant decrease in TG content compared to RBO group. Phospholipid content was significantly increased in DGR group compared to RBO group. This unique physicochemical property of DAG oil is possible due to the presence of a free hydroxyl group in the structure. The cooking properties of DAG oil are similar to those of conventional cooking oil. But the absence of a fatty acid in the sn-2 position of a 1,3-diglyceride creates a different MAG after normal digestion. This digestive product known as 1/3-MAG, as opposed to 2-MAG formed during digestion of conventional oil i.e. TAG oils, is not efficient a substrate for TAG re-synthesis in the intestinal lumen. As a result, 1/3-MAG must follow the 2-MAG pathway to a much slower degree or an alternative pathway for TAG re-synthesis. This alternative pathway is commonly described as a glycerol phosphate pathway. It involves the utilization of glycerol -3 as the starting point for TAG synthesis. For 1-MAG to follow this pathway, it must be hydrolysed to glycerol, which releases a free fatty acid (FFA) that could be available for TAG re-synthesis or potentially for energy utilization. As a result, postprandial elevations in TAG-rich lipoproteins are lowered significantly after consumption of DAG rich oil $(36,7)$.

Table 4 depicts the lipid profile of EM in different dietary groups. TG, TC and phospholipid content were significantly decreased in experimental DGR group compared to RBO (control) group.

Table 5 represents the liver HMG CoA-Mevalonate ratio which in turn represented the HMG CoA reductase activity. DGR group (experimental) showed significant decrease in HMG CoA reductase activity compared to RBO group. Therefore, it can be concluded that cholesterol biosynthesis was down regulated in DGR group.

Measurement of plasma leptin is an excellent index of obesity. Table 5 showed the plasma leptin content of rats of different dietary group. Leptin is a protein hormone a product of ob gene containing 167 amino acids with important effects in regulating body weight, metabolism and reproductive function. It is secreted from white adipose tissues and decreased hunger and food intake by inhibiting 


\section{R. Dhara, P. Dhar and M. Ghosh}

Table 4 Lipid profile of erythrocyte membrane (EM) ghost of different dietary groups.

\begin{tabular}{cccc}
\hline Groups & $\begin{array}{c}\text { TG } \\
(\mathrm{mg} / \mathrm{mg} \text { of protein })\end{array}$ & $\begin{array}{c}\text { Cholesterol } \\
(\mathrm{mg} / \mathrm{mg} \text { of protein })\end{array}$ & $\begin{array}{c}\text { Phospholipid } \\
(\mathrm{mg} / \mathrm{mg} \text { of protein })\end{array}$ \\
\hline RBO & $0.42 \pm 0.23^{*}$ & $0.07 \pm 0.36$ & $0.49 \pm 0.06^{\#}$ \\
DGR & $0.38 \pm 0.21^{*}$ & $0.05 \pm 0.34$ & $0.57 \pm 0.17^{\#}$ \\
\hline
\end{tabular}

All values are means of 8 rats/ diet \pm SEM; (See Fig. 1 for other abbreviations)

$*$ RBO vs. DGR significant, $p<0.01$

${ }^{\#}$ RBO vs. DGR significant, $p<0.01$

\#\#B vs. DGR significant, $\mathrm{p}<0.05$

Table 5 Liver HMG CoA-Mevalonate ratio and leptin content $(\mathrm{ng} / \mathrm{mL})$ in different dietary groups.

\begin{tabular}{ccc}
\hline Groups & HMG CoA-Mevalonate ratio & Leptin content $(\mathrm{ng} / \mathrm{mL})$ \\
\hline RBO & $1.88 \pm 0.05^{\mathrm{p}}$ & $2.63 \pm 0.165$ \\
DGR & $1.32 \pm 0.11^{\mathrm{p}}$ & $2.11 \pm 0.023$ \\
\hline
\end{tabular}

All values are means of 8 rats/ diet \pm SEM; (See Fig. 1 for other abbreviations)

${ }^{\mathrm{p}} \mathrm{RBO}$ vs. DGR significant, $\mathrm{p}<0.05$

gene expression of neuropeptide Y(NPY). Leptins effects on body weight are mediated through effects on hypothalamic centers that control feeding behavior and hunger, body temperature and energy expenditure. Blood concentration of leptin is usually increased in obese humans, suggesting that they are in some way insensitive to leptin, rather than suffering from leptin deficiency. DGR (experimental) group showed significant decrease in leptin content compared to RBO group and thus shows anti-obese properties.

\section{Conclusion}

Obesity is a difficult condition to treat. Energy restriction and increased physical activity are the first lines of therapy. Replacing a portion of TAG with DAG rich oil prepared from rice bran oil could be a promise that can control obesity, an alarming lifestyle disease of modern population. The plasma lipid profile indicates that DAG-rich rice bran oil reduces TG and TC. DAG-rich rice bran oil can down regulate cholesterol biosynthesis by inhibiting the activity of HMG-CoA reductase, a rate-limiting enzyme for cholesterol biosynthesis.

\section{Acknowledgement}

The work was funded by University Grant Commission (UGC), Govt. of India. Authors are thankful to Dr. Santinath Ghosh, Dept. of Chemical Technology, University of
Calcutta for his support.

\section{References}

1) Hibi, M.; Sugiura, Y.; Yokoyama, R.; Takase, H.; Shiiba, D.; Meguro, S.; Katashima, M.; Shimizu, A.; Tokimitsu, I. The short-term effect of DAG oil consumption on total and dietary fat utilization in overweight women. Obesity 2011, 19, 536-540(2011).

2) Yasukawa, T.; Katsuragi, Y. Diacylglecerol Oil. AOCS press, Champaign, Illinois (2004).

3) Nagao, T.; Watanabe, H.; Goto, N.; Onizawa, K.; Taguchi, H.; Matsuo, N.; Yasukawa, T.; Tsushima, R.; Shimasaki, H.; Itakura, H. Dietary DAG suppresses accumulation of body fat compared to triacylglycerol in men in a double-blind controlled trial. J. Nutr. 130, 792797 (2000)

4) Couillard C., Bergeron N., Prud'homme D., Bergeron J., Tremblay A., Bouchard C., Mauriège P., Després J. P. Postprandial Triglyceride Response in Visceral Obesity in Men, Diabetes 47, 953-960 (1998).

5) Kondo, H.; Hase, T.; Murase, T.; Tokimitsu, I. Digestion and assimilation features of dietary DAG in the rat small intestine. Lipids 38, 25-30 (2003).

6) Shimada, A.; Ohashi, K. Interfacial and emulsifying properties of DAG. Food Sci. Technol. Res. 2, 142-147 (2003).

7) Tada, N.; Watanabe, H.; Matsuo, N.; Tokimitsu, I.; Okazaki, M. Dynamics of postprandial remnant-like lipoprotein particles in serum after loading of DAGs. Clin. 


\section{Dietary Effects of DAG-rich Rice Bran Oil}

Chim. Acta. 311, 109-117(2001).

8) Taguchi, H.; Watanabe, H.; Onizawa, K.; Nagao, T.; Gotoh, N.; Yasukawa, T.; Tsushima, R.; Shimasaki, H.; Itakura, H. Double-blind controlled study on the effects of dietary DAG on postprandial serum and chylomicron triacylglycerol responses in healthy humans. $J$. Am. Coll. Nutr. 19, 789-796(2000).

9) Kamphuis, M. M.; Mela, D. J.; Westerterp-Plantenga, M. S. DAGs affect substrate oxidation and appetite in humans. Am. J. Clin. Nutr. 77, 1133-1139(2003).

10) Saito, S.; Yamaguchi, T.; Shoji, K.; Hibi, M.; Sugita, T.; Takase, H. Effect of low concentration of DAG on mildly postprandial hypertriglyceridemia. Atherosclerosis 213, 539-544(2010).

11) Berger, A.; Rein, D.; Schafer, A.; Monnard, I.; Gremaud, G.; Lambelet, P.; Bertoli, C. Similar cholesterollowering properties of rice bran oil, with varied gamma-oryzanol, in mildly hypercholesterolemic men. Eur. J. Nutr. 44, 163-173(2005).

12) Cicero, A. F.; Gaddi, A. Rice bran oil and gamma-oryzanol in the treatment of hyperlipoproteinaemias and other conditions. Phytother. Res. 15, 277-289 (2001).

13) Wilson, T. A.; Ausman, L. M.; Lawton, C. W.; Hegsted, D. M.; Nicolosi, R. J. Comparative cholesterol lowering properties of vegetable oils: beyond fatty acids. J. Am. Coll. Nutr. 19, 601-607(2000).

14) Rukmini, C.; Raghuram, T. C. Nutritional and biochemical aspects of the hypolipidemic action of rice bran oil: a review. J. Am. Coll. Nutr. 10, 593-601 (1991).

15) Sugano, M.; Tsuji, E. Rice bran oil and cholesterol metabolism. J. Nutr. 127, 521S-524S (1997).

16) Dhara, R.; Dhar, P.; Ghosh, M. Dietary Effects of DAG rich mustard oil on lipid profile of normocholesterolemic and hypercholesterolemic rats. J. Food Sci. Technol.:DOI: 10.1007/s13197-13011-10388-y(2011).

17) Macala, L. J.; Yu, R. K.; Ando, S. Analysis of brain lipids by high performance thin-layer chromatography and densitometry. J. Lipid Res. 24, 1243-1250(1983).

18) Litchfield, C. Analysis of triglycerides. Academic press, New York (1972).

19) Jones, J. H.; Foster, C. A. A salt mixture for use with basal diet either low or high in phosphorus. J. Nutr. 24, 245-256 (1942)

20) Allain, C. C.; Poon, L. S.; Chan, C. S.; Richmond, W.; $\mathrm{Fu}$, P. C. Enzymatic determination of total serum cholesterol. Clin. Chem. 20, 470-475(1974).

21) Warnick, G. R.; Nguyen, T.; Albers, A. A. Comparison of improved precipitation methods for quantification of high-density lipoprotein cholesterol. Clin. Chem. 31, 217-222 (1985).

22) Bucolo, G.; David, H. Quantitative determination of serum triglycerides by the use of enzymes. Clin. Chem.,
19, 476-482(1973).

23) Rose, H. G.; Oklander, M. Improved Procedure for the Extraction of Lipids from Human Erythrocytes. $J$. Lipid Res. 6, 428-431(1965).

24) Bligh, E. G.; Dyer, W. J. A rapid method of total lipid extraction and purification. Can. J. Biochem. Physiol. 37, 911-917 (1959).

25) Lowry, O. H.; Rosebrough, N. J.; Farr, A. L.; Randall, R. J. Protein measurement with the Folin phenol reagent. J. Biol. Chem. 193, 265-275 (1951).

26) Chen, P. S.; Toribara, T. Y.; Warner, H. Microdetermination of phosphorous. Anal. Chem. 28, 1756-1758 (1956).

27) Rao, A. V.; Ramakrishnan, S. Indirect assessment of hydroxymethylglutaryl-CoA reductase (NADPH) activity in liver tissue. Clin. Chem. 21, 1523-1525(1975).

28) Scheffe, H. The Analysis of variance. In, vol Sec. 2.2; Sec. 3.6. John Wiley \& Sons, New York, 73-74(1961).

29) Murase, T.; Mizuno, T.; Omachi, T.; Onizawa, K.; Komine, Y.; Kondo, H.; Hase, T.; Tokimitsu, I. Dietary DAG suppresses high fat and high sucrose diet-induced body fat accumulation in C57BL/6J mice. J. Lipid Res. 42, 372-378(2001).

30) Taguchi, H.; Nagao, T.; Watanabe, H.; Onizawa, K.; Matsuo, N.; Tokimitsu, I.; Itakura, H. Energy value and digestibility of dietary oil containing mainly 1,3-DAG are similar to those of triacylglycerol. Lipids 36, 379$382(2001)$

31) Maki, K. C.; Davidson, M. H.; Tsushima, R.; Matsuo, N.; Tokimitsu, I.; Umporowicz, D. M.; Dicklin, M. R.; Foster, G. S.; Ingram, K. A.; Anderson, B. D.; Frost, S. D.; Bell, M. Consumption of DAG oil as part of a reducedenergy diet enhances loss of body weight and fat in comparison with consumption of a triacylglycerol control oil. Am. J. Clin. Nutr. 76, 1230-1236 (2002).

32) Watanabe, H.; Tokimitsu, I. Diacylglecerol oil. In. AOCS press, 30-45 (2004).

33) Watanabe, H.; Onizawa, K.; Taguchi, H. Nutritional Characterization of DAGs in rats. J. Oleo Sci. 46, 301307 (1977).

34) Ikeda, I.; Yanagita, T. Fate of Hydrolysis Product Originating from DAG and Triacylglycerol in the Intestine. In: Diacylglecerol Oil. AOCS press, Champaign, Illinois, 64-69 (2004).

35) Murase, T.; Aoki, M.; Wakisaka, T.; Hase, T.; Tokimitsu, I. Anti-obesity effect of dietary DAG in C57BL/6J mice: dietary DAG stimulates intestinal lipid metabolism. $J$. Lipid Res. 43(8), 1312-1319(2002).

36) Murata, M.; Hara, K.; Ide, T. Alteration by DAGs of the transport and fatty acid composition of lymph chylomicrons in rats. Biosci. Biotechnol. Biochem. 58, 1416-1419 (1994). 